\title{
Bone losses in obese, ovariectomized rats appear to be independent from sclerostin- induced inhibition of the Wnt/ $\beta$-catenin pathway
}

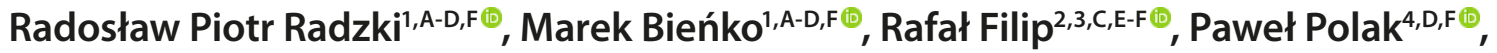 \\ Joanna Michalik (Wolska) ${ }^{5, B, F}$ \\ ${ }^{1}$ Department of Animal Physiology, Faculty of Veterinary Medicine, University of Life Sciences, Lublin, Poland \\ ${ }^{2}$ Department of Gastroenterology of Clinical Hospital 2, University of Rzeszow, Poland \\ ${ }^{3}$ Department of Endoscopy, Institute of Rural Health, Lublin, Poland \\ ${ }^{4}$ Department of Orthopaedics and Traumatology, Medical University, Lublin, Poland \\ ${ }^{5}$ Chair of Oncology and Environmental Health Care, Faculty of Health Sciences, Medical University, Lublin, Poland \\ A - Research concept and design, B - Collection and/or assembly of data, C - Data analysis and interpretation, \\ $D$ - Writing the article, E-Critical revision of the article, F- Final approval of article
}

Radzki RP, Bieńko M, Filip R, Polak P, Michalik (Wolska) J. Bone losses in obese, ovariectomized rats appear to be independent from sclerostininduced inhibition of the Wnt/ $\beta$-catenin pathway. Ann Agric Environ Med. 2020; 27(3): 394-400. doi: 10.26444/aaem/110527

\begin{abstract}
Introduction. Overweight and obesity, as well as a gonadal function, are pivotal factors influencing bone tissue metabolism. Materials and method. The aim of the study was to determine the effect of dietary induced obesity (DIO) on bone tissue metabolism in sham-operated (SHO) or ovariectomized (OVX) adult female Wistar rats. Additionally, the influence of DIO in SHO or OVX on the concentration of sclerostin in the blood serum was analyzed. After SHO or OVX, the rats were placed in groups $(\mathrm{n}=8)$ and either received a standard diet $(11.5 \mathrm{MJ} / \mathrm{kg})(\mathrm{SHO}-\mathrm{CON}$; OVX-CON) or a high-energy diet $(17.6 \mathrm{MJ} / \mathrm{kg})$ (SHO-FAT; OVX-FAT). The experiment lasted for 90 days and allowed for the establishment of osteopenia in OVX females and obesity in the rats that had received the high-energy diet.

Results. The results of the study demonstrate that obesity or/and ovariectomy increases the resorption of femora and tibiae, hence decreasing the densitometric and mechanical parameters affecting the bone structure in adult females rats. The strongest osteodegenerative effect was seen in the OVX-FAT females. Interestingly, the degree of bone tissue degradation caused exclusively by ovariectomy was similar to that found in the obese sham-operated rats.

Conclusions. Bone losses invoked by DIO seem to be independent from the Wnt/ $\beta$-catenin pathway inhibition induced by sclerostin. While further study is necessary, the obtained results suggest that the usage of sclerostin anti-body in the treatment of osteoporosis can be ineffective, and in obese patients the undertaking of such therapy should be reassessed.
\end{abstract}

\section{Key words}

dietary induced obesity, bone, sclerostin, pQCT, DXA, rats, ovariectomy

\section{INTRODUCTION}

Alarming data published by the WHO indicate that in 2016, about $39 \%$ of all men and women aged 18 and over were overweight or obese. Conditions of overweight and obesity are also noted in children and adolescents and affect $18 \%$ of all who are between 5 - 19 years of age. The excessive accumulation of body fat leading to conditions of overweight and obesity results from an imbalance between intake and expenditure of energy, mainly because of insufficient physical activity. In the pathogenesis of obesity, however, genetic, environmental and cultural predisposition, hormonal status, as well as other factors play key roles $[1,2]$.

The consequences of overweight and obesity are multidirectional and include problems that are sociological, economical, and predominantly health-related [3]. The conditions of overweight and obesity increase the risk of

Address for correspondence: Marek Bieńko, Department of Animal Physiology Faculty of Veterinary Medicine,University of Life Sciences in Lublin, Poland

E-mail: marek.bienko@up.lublin.pl

Received: 12.05.2019; accepted: 05.07.2019; first published: 24.07.2019 metabolic syndrome, some types of cancer, diabetes type II, endocrinal disorders, osteoarthritis and more $[4,5]$. The effect of the fat tissue on the metabolism of bone tissue is still discussed and two main opinions clash. The first underlines the positive influence of fat tissue accumulation and increased body weight on bone metabolism $[6,7]$, whereas the other demonstrates that being overweight or obese stimulates the degradation of bone tissue and increases the risk of osteopenia and osteoporosis development [8].

Sclerostin is a protein synthetized mainly by mature osteocytes. After binding with low-density lipoprotein receptor-related protein receptors LRP5 and LRP 6, it inhibits the activity of the canonical signaling pathway $\mathrm{Wnt} / \beta$-catenin which activates osteoblast metabolism [9]. Therefore, an increased synthesis and concentration of sclerostin inhibits bone tissue formation and stimulates its resorption.

In recent years, much attention has been paid to the role of the Wnt/beta-catenin pathway and sclerostin in affecting the activity of this pathway. The Wnt pathway is one of the intracellular routes of signal transmission [10], and the Wnt family of proteins includes 19 secreted glycoproteins, which 
interact with the cell via activation of lipoprotein receptors (LPR5 and LPR6) [11]. These proteins are involved in the processes of cell apoptosis, differentiation, proliferation, morphogenesis, migration and polarization $[10,12]$. The Wnt pathway may involve the activation of a canonical betacatenin dependent pathway and/or a few non-canonical beta-catenin independent pathways. At the same time, the transformation of these cells to chondroblasts or adipocytes is limited. Activation of the canonical Wnt/beta-catenin pathway stimulates cell differentiation into osteoblasts and inhibits apoptosis of mature osteoblasts [13]. In addition, by stimulating osteoprotegrin synthesis, it inhibits proliferation and osteoclast maturation.

Sclerostin is one of the key proteins regulating remodeling of bone tissue. It is produced by mature osteocytes to suppress osteosynthesis processes and maintain balance between osteoclast bone resorption and osteoblastic formation [14]. Sclerostin binds to the LRP5 and LRP6 receptors, inhibiting the Wnt/beta-catenin pathway [15]. Numerous reports suggest that sclerostin deficiency positively correlates with high bone mass, and sclerostin antibodies can be useful in osteoporosis therapy [16]. However, the results of some studies undermine the general conception of sclerostin role in bone metabolism. Register et al. [17] indicated a positive correlation between the plasma level of sclerostin and BMD. Similarly, Polyzos et al. [18] documented a decrease in the sclerostin level in women with postmenopausal osteoporosis in relation to the non-osteoporotic. Additionally, they noted a positive correlation between either the lumbar spine BMD or lumbar spine T-score, with serum sclerostin concentration. Osteoporotic patients demonstrated a higher BMI.

In contrast to the above, Armamento-Villareal et al. [19] observed an elevation of the blood serum sclerostin concentration in formerly obese older patients who had decreased their body weight by following a properly calculated diet. Increased sclerostin concentration was also documented in children with obesity [20]. Interestingly, in both cases, the elevated level of sclerostin induced disturbances in bone tissue metabolism and structure.

\section{OBJECTIVES}

The present study was undertaken to verify the exclusive and combinational effect of dietary-induced obesity (DIO) and ovariectomy (OVX) on bone tissue metabolism in adult female rats. Changes in blood serum sclerostin concentration were analyzed independently to hormonal and nutritional status.

\section{MATERIALS AND METHOD}

Animal procedures. The study was conducted on 32 female Wistar rats at the age of 3 months, with an initial body mass of $250 \mathrm{~g} \pm 20$. After acclimatization, the rats were randomly placed into two groups - sham-operation $(\mathrm{SHO})(\mathrm{n}=16)$ or ovariectomy OVX $(n=16)$. Seven days after surgery, the SHO and OVX females were subsequently sub-grouped $(n=8$ in each group), one of which received standard diet $(11.5 \mathrm{MJ} / \mathrm{kg})$ and the other, a high-energy diet (17.6 MJ/kg) ('Morawski', Kcynia, Poland). The formula of the standard diet is based on the recommendations of the National Research Council in the area of Nutrient Requirements of Laboratory Animals, while the high-energy diet was created on the basis of a standard diet [21]. The experimental feeding was aimed at establishing dietary-induced obesity (DIO) and was followed for 90 days, as this period allowed for the establishment of osteopenia in OVX females. The rats were housed individually in cages with ad libitum access to food and water. After 90 days, the rats were euthanized. Serum samples obtained at the time of their killing were stored for further analysis. After exsanguination, the femora and tibiae were dissected, cleaned of soft tissue and frozen at $-30^{\circ} \mathrm{C}$ for further analysis.

The experimental protocol was approved by the II Local Animal Welfare Committee in Lublin, Poland,

Dual X-ray Absorptiometry (DXA) analysis of total skeleton and isolated femora and tibiae. Planar bone mineral density (BMD), bone mineral content (BMC) and area (Ar) of whole isolated right femora (f.BMD; f.BMC; f.Ar) and tibiae (t.BMD; t.BMC; t.Ar) were established using a Norland Excell Plus Densitometer (Fort Atkinson, Wisconsin, USA) and Illuminatus Small Subject Scan v.4.5 software.

Peripheral quantitative computed tomography (pQCT). The right femora and tibiae were scanned by peripheral quantitative computed tomography (pQCT), using the XCT Research SA Plus system with software version 6.2 C (Stratec Medizintechnik GmbH, Pforzheim, Germany). The scans were performed perpendicular to the long axis in the distal femora metaphysis (DFM) $(5 \mathrm{~mm}$ from distal end) and the proximal tibiae metaphysis (PTM) $(5 \mathrm{~mm}$ from the proximal end) for analysis of the trabecular bone compartment, and in the mid-shaft femora (MFD) and tibiae (MTD) of diaphysis (50\% of bone length) for the analysis of the cortical compartment. The scan line was adjusted using scout view after the initial scan of the pQCT system. Initial scan was performed at $10 \mathrm{~mm} / \mathrm{s}$, and CT-scan at $4 \mathrm{~mm} / \mathrm{s}$. As cortical and trabecular structure are separated by the areal distribution of both bone compartments, by default, $55 \%$ of the outer bone area is concentrically separated and defined as the cortical-subcortical region, while the remaining $45 \%$ inner core is defined as trabecular bone. Upon completion of scanning, the algorithm of the XCT Research software base on the above settings (threshold, contour mode, peel mode, cortical mode) allow for automatic calculation of the densitometric and architectonical properties. Analyses of trabecular bone were performed with a contour mode of 2 and a peel mode of 20 (threshold $\left.610 \mathrm{mg} / \mathrm{cm}^{3}\right)$. The following DFM/PTM parameters were determined: total bone mineral content (Tot.BMC), total volumetric bone mineral density (Tot.vBMD), total bone area (Tot.Ar), trabecular bone area (Tb.Ar), trabecular bone mineral content (Tb.BMC) and trabecular volumetric bone mineral density (Tb.vBMD). Cortical mode 1 (threshold $710 \mathrm{mg} / \mathrm{cm}^{3}$ ) was used to obtain total and cortical volumetric bone mineral density (Tot. vBMD; Ct.vBMD), bone mineral content (Tot.BMC; Ct.BMC) and cortical area (Ct.Ar). Total area (Tot.Ar), pericortical (Peri.C) and endocortical (Endo.C) perimeters, cortical thickness (Ct.Th) were measured using contour mode 1 (threshold $710 \mathrm{mg} / \mathrm{cm}^{3}$ ) to define the outer bone edge and peel mode 2 (threshold $400 \mathrm{mg} / \mathrm{cm}^{3}$ ) to separate the cortical and subcortical/medullary compartments. The measurement of the thickness Ct.Th, Endo.C and Peri.C were performed using a circular ring model where the medullary area 
was calculated as the total area minus cortical area. Daily calibration of the system with the use of hydroxyapatite containing quality assurance phantom (pQCT QA-Phantom) preceded the measurements.

Mechanical properties. The mechanical parameters of the isolated femora and tibiae were ascertained by the 3-point bending test, using a ZwickRoell Z010 (ZwickRoell GmbH \& Co. KG, Ulm, Germany) universal testing machine equipped with a $1 \mathrm{kN}$ measuring head (Xforce HP series). The analyzed bones were investigated as a tube model. The internal and external diameters required in the analysis of a tube model, were estimated by pQCT. In the 3-point bending test, the bone was placed on 2 holders, and the force was applied downward, perpendicularly to the horizontal axis, at the midpoint of the bone. The load was increased until the bone broke. The received data were analyzed using testXpert II 3.1 software and the ultimate strength $\left(\mathrm{F}_{\max }\right)$, work to ultimate strength ratio $\left(\mathrm{W} / \mathrm{F}_{\max }\right)$, and the Young modulus $\left(\mathrm{E}_{\bmod }\right)$ were measured.

Biochemical markers of bone tissue metabolism. Serum concentration of osteocalcin (OC) (Immunodiagnostic Systems, UK), C-terminal telopeptides of type I collagen (CTX-I) (Immunodiagnostic Systems, UK) and sclerostin (LifeSpan BioSciences, USA) were measured by an enzymelinked immunosorbent assay (ELISA), utilizing the respective commercial kits. Alcaline phosphatase (ALP) activity, concentration of the total cholesterol, triglicerides, highdensity lipoproteins (HDL) and low-density lipoproteins (LDL) were also measured spectrophotometrically by way of commercial kits (Alphadiagnostic, Poland) and a Mindray BS 120 apparatus (Mindray, China).

Statistical analysis. The results were presented as mean values \pm S.E.M, while one-way analysis of variance (ANOVA) was applied to test for significant differences among the experimental groups. To establish significant differences between individual experimental groups, significant ANOVA's were followed by the post hoc Tukey test for multiple comparisons. Analysis was also performed of the correlation between serum concentration of sclerostin in relation to the level of CTX, as well as to mechanical parameters. Differences were considered significant at $\mathrm{P}<0.05$. Statistical analyses were performed using STATISTICA software v. 13.0 (Tibco Software Inc., USA).

\section{RESULTS}

Densitometry (DXA) of the isolated femur and tibiae. The densitometry (DXA) of isolated femur and tibiae indicated that a high-energy diet decreased the planar BMD and the $\mathrm{BMC}$ of femur and tibiae in SHO females (SHO-FAT group) $(\mathrm{P}<0.05)$ in relation to the SHO-CON group (Tab. 1). A significant decrease of the analyzed parameter of the femur and tibiae in SHO-FAT and OVX-CON rats was noted $(\mathrm{P}<$ 0.05). Planar BMD and the BMC values in both groups were at a similar level, while the lowest values of planar BMD and the BMC were noted in OVX-FAT rats $(\mathrm{P}<0.05)$ (Tab. 1). In addition, a higher f.Ar and t.Ar were noted in the bones isolated from OVX than in SHO females (Tab. 1). Thus, the high-energy diet tended to lower values of the femur and
Table 1. Densitometric (DXA) measurements of femur (f) and tibiae (t) isolated from sham-operated (SHO) and ovariectomized (OVX) rats fed the standard (CON) or high-energy diet (FAT), respectively

\begin{tabular}{lcccc}
\hline & SHO-CON & SHO-FAT & OVX-CON & OVX-FAT \\
\hline f.BMC $(\mathrm{g})$ & $0.485 \pm 0.009$ & $0.453 \pm 0.002^{\#}$ & $0.454 \pm 0.005^{\#}$ & $0.437 \pm 0.003^{\# *}$ \\
\hline f.BMD $\left(\mathrm{g} / \mathrm{cm}^{2}\right)$ & $0.137 \pm 0.001$ & $0.130 \pm 0.001^{\#}$ & $0.130 \pm 0.001^{\#}$ & $0.125 \pm 0.001$ \\
\hline f.Ar $\left(\mathrm{cm}^{2}\right)$ & $3.57 \pm 0.002$ & $3.46 \pm 0.03^{\#}$ & $3.58 \pm 0.03^{\#}$ & $3.51 \pm 0.02$ \\
\hline t.BMC $(\mathrm{g})$ & $0.327 \pm 0.0004$ & $0.319 \pm 0.002$ & $0.318 \pm 0.001^{\#}$ & $0.310 \pm 0.002^{\# *}$ \\
\hline t.BMD $\left(\mathrm{g} / \mathrm{cm}^{2}\right)$ & $0.105 \pm 0.001$ & $0.102 \pm 0.001^{\#}$ & $0.100 \pm 0.001^{\#}$ & $0.096 \pm 0.001^{\# *}$ \\
\hline t.Ar $\left(\mathrm{cm}^{2}\right)$ & $3.10 \pm 0.003$ & $3.08 \pm 0.02$ & $3.15 \pm 0.022$ & $3.13 \pm 0.02$
\end{tabular}

Results are the means \pm S.E.M. $(n=8)$. \# vs. SHO-CON; ${ }^{*} v s$. SHO-FAT; $\ddagger v s$. OVX-CON, where $\mathrm{P} \leq$ 0.05 by ANOVA and post hoc Tukey test.

f.BMC-femoral bone mineral content; $f$.BMD-femoral planar bone mineral density; f.Ar-femoral area; t.BMC-tibiae bone mineral content; t.BMD-tibiae planar bone mineral density; t.Ar-tibiae area.

tibiae area in both SHO and OVX rats in relation to the animals fed the standard diet.

Table 2. Tomographic ( $\mathrm{PQCT}$ ) measurements of cortical and trabecular compartments in mid-shaft (MFD) and distal metaphysis (PFM) of femora isolated from sham-operated (SHO) and ovariectomized (OVX) rats fed the standard (CON) or high-energy diet (FAT), respectively

\begin{tabular}{|c|c|c|c|c|}
\hline & SHO-CON & SHO-FAT & OVX-CON & OVX-FAT \\
\hline \multicolumn{5}{|c|}{ Cortical compartment } \\
\hline $\begin{array}{l}\text { Tot.BMC } \\
(\mathrm{mg} / \mathrm{mm})\end{array}$ & $11.26 \pm 0.07$ & $10.44 \pm 0.15^{\#}$ & $10.52 \pm 0.17^{\#}$ & $9.94 \pm 0.13^{\# x \neq}$ \\
\hline $\begin{array}{l}\text { Tot.vBMD } \\
\left(\mathrm{mg} / \mathrm{mm}^{3}\right)\end{array}$ & $1050.03 \pm 11.06$ & $982.10 \pm 13.40^{\#}$ & $1006.17 \pm 3.70^{\#}$ & $919.95 \pm 20.95^{\mu^{*} \neq}$ \\
\hline $\begin{array}{l}\text { Tot.Ar } \\
\left(\mathrm{mm}^{2}\right)\end{array}$ & $10.71 \pm 0.08$ & $11.06 \pm 0.25$ & $9.42 \pm 0.17^{\# *}$ & $9.96 \pm 0.15^{\#^{*} \neq}$ \\
\hline $\begin{array}{l}\text { Ct.BMC } \\
(\mathrm{mg} / \mathrm{mm})\end{array}$ & $10.95 \pm 0.13$ & $10.15 \pm 0.06^{\#}$ & $10.10 \pm 0.15^{\#}$ & $9.66 \pm 0.21^{\# \neq}$ \\
\hline $\begin{array}{l}\text { Ct.vBMD } \\
\left(\mathrm{mg} / \mathrm{mm}^{3}\right)\end{array}$ & $1488.40 \pm 7.75$ & $1396.46 \pm 11.24^{\#}$ & $1415.25 \pm 8.24^{\#}$ & $1373.80 \pm 16.13^{\# \neq}$ \\
\hline $\begin{array}{l}\text { Ct.Ar } \\
\left(\mathrm{mm}^{2}\right)\end{array}$ & $6.47 \pm 0.04$ & $6.53 \pm 0.04$ & $5.55 \pm 0.07^{\# *}$ & $5.52 \pm 0.03^{\# *}$ \\
\hline $\begin{array}{l}\text { Endo.C } \\
(\mathrm{mm})\end{array}$ & $7.30 \pm 0.09$ & $7.53 \pm 0.16^{\#}$ & $6.97 \pm 0.11^{*}$ & $7.47 \pm 0.14^{\ddagger}$ \\
\hline $\begin{array}{l}\text { Peri.C } \\
(\mathrm{mm})\end{array}$ & $11.60 \pm 0.30$ & $11.79 \pm 0.26$ & $10.88 \pm 0.14^{\#^{*}}$ & $11.19 \pm 0.08^{*}$ \\
\hline $\begin{array}{l}\text { Ct.Th } \\
(\mathrm{mm})\end{array}$ & $0.685 \pm 0.02$ & $0.672 \pm 0.02$ & $0.622 \pm 0.01^{\# *}$ & $0.592 \pm 0.01^{\#^{*}}$ \\
\hline
\end{tabular}

Trabecular compartment

\begin{tabular}{lcccc}
\hline $\begin{array}{l}\text { Tot.BMC } \\
(\mathrm{mg} / \mathrm{mm})\end{array}$ & $15.49 \pm 1.14$ & $15.94 \pm 0.65$ & $13.94 \pm 0.67$ & $14.81 \pm 0.49$ \\
\hline $\begin{array}{l}\text { Tot.vBMD } \\
\left(\mathrm{mg} / \mathrm{mm}^{3}\right)\end{array}$ & $873.47 \pm 48.51$ & $777.02 \pm 34.29$ & $757.73 \pm 28.40$ & $752.09 \pm 33.96$ \\
\hline $\begin{array}{l}\text { Tot.Ar } \\
(\mathrm{mm})\end{array}$ & $17.71 \pm 0.25$ & $20.61 \pm 0.51$ & $18.39 \pm 0.56$ & $19.93 \pm 0.38$ \\
\hline $\begin{array}{l}\mathrm{Tb} . \mathrm{BMC} \\
(\mathrm{mg} / \mathrm{mm})\end{array}$ & $4.80 \pm 0.10$ & $4.35 \pm 0.05^{\#}$ & $3.67 \pm 0.08^{\# *}$ & $3.51 \pm 0.09^{\# *}$ \\
\hline $\begin{array}{l}\text { Tb.vBMD } \\
\left(\mathrm{mg} / \mathrm{mm}^{3}\right)\end{array}$ & $528.07 \pm 9.91$ & $470.75 \pm 8.74^{\#}$ & $426.72 \pm 14.84^{\# *}$ & $397.99 \pm 8.51^{\# *}$ \\
\hline $\begin{array}{l}\text { Tb.Ar } \\
\left(\mathrm{mm}{ }^{2}\right)\end{array}$ & $7.96 \pm 0.1$ & $9.11 \pm 0.12^{\#}$ & $8.27 \pm 0.03^{*}$ & $8.95 \pm 0.05^{\# \neq}$ \\
\hline
\end{tabular}

Results are the means \pm S.E.M. $(\mathrm{n}=8)$. \# vs. SHO-CON; * vs. SHO-FAT; $\neq v$ s. OVX-CON, where $\mathrm{P} \leq$ 0.05 , by ANOVA and post hoc Tukey test.

Abbreviations for cortical bone tissue: Tot.BMC - Total slice bone mineral content; Tot.vBMD - total slice volumetric bone mineral density; $\mathrm{Tot}$. $\mathrm{Ar}$ - total slice bone area; $\mathrm{Ct}$. $\mathrm{Ar}$ - cortical bone area; Ct.BMC - cortical bone mineralcont; Ct.Th - cortical thickness; Peri.C - periosteal circumference; Endo.C-endocortical circumference. Abbreviations for trabecular bone tissue: Tot.BMC - total slice bone mineral content; Tot.vBMD - total slice volumetric bone mineral density; $\mathrm{Tot} . \mathrm{Ar}$ - total slice bone area; $\mathrm{Tb} . \mathrm{Ar}$ - trabecular bone area; Tb.BMC - trabecular bone mineral content; Tb.vBMD - trabecular volumetric bone mineral density. 
Table 3. Tomographic ( $\mathrm{pQCT}$ ) measurements of cortical and trabecular compartments in mid-shaft (MTD) and distal metaphysis (DTM) of tibiae isolated from sham-operated (SHO) and ovariectomized (OVX) rats fed the standard (CON) or high-energy diet (FAT), respectively.

\begin{tabular}{|c|c|c|c|c|}
\hline & SHO-CON & SHO-FAT & OVX-CON & OVX-FAT \\
\hline \multicolumn{5}{|c|}{ Cortical compartment } \\
\hline $\begin{array}{l}\text { Tot.BMC } \\
(\mathrm{mg} / \mathrm{mm})\end{array}$ & $7.01 \pm 0.12$ & $6.62 \pm 0.12$ & $6.38 \pm 0.24^{\#}$ & $6.34 \pm 0.05^{\#}$ \\
\hline $\begin{array}{l}\text { Tot.vBMD } \\
\left(\mathrm{mg} / \mathrm{mm}^{3}\right)\end{array}$ & $1140.47 \pm 8.67$ & $1094.06 \pm 21.68^{\#}$ & $1075.13 \pm 6.74^{\#^{*}}$ & $1080.69 \pm 11.49^{\# *}$ \\
\hline $\begin{array}{l}\text { Tot.Ar } \\
\left(\mathrm{mm}^{2}\right)\end{array}$ & $5.82 \pm 0.15$ & $5.99 \pm 0.14$ & $4.98 \pm 0.13^{\#}$ & $5.25 \pm 0.10^{\#}$ \\
\hline $\begin{array}{l}\text { Ct.BMC } \\
(\mathrm{mg} / \mathrm{mm})\end{array}$ & $6.57 \pm 0.04$ & $6.27 \pm 0.06^{\#}$ & $6.24 \pm 0.03^{\#}$ & $5.91 \pm 0.08^{\# * \neq}$ \\
\hline $\begin{array}{l}\text { Ct.vBMD } \\
\left(\mathrm{mg} / \mathrm{mm}^{3}\right)\end{array}$ & $1464.60 \pm 4.99$ & $1427.20 \pm 6.36^{\#}$ & $1429.75 \pm 7.25^{\#}$ & $1381.88 \pm 14.39^{\# * \neq}$ \\
\hline $\begin{array}{l}\text { Ct.Ar } \\
\left(\mathrm{mm}^{2}\right)\end{array}$ & $3.97 \pm 0.08$ & $3.98 \pm 0.20$ & $3.31 \pm 0.12^{\# *}$ & $3.35 \pm 0.11^{\# *}$ \\
\hline $\begin{array}{l}\text { Endo.C } \\
(\mathrm{mm})\end{array}$ & $4.82 \pm 0.04$ & $5.01 \pm 0.03$ & $4.56 \pm 0.02^{\# *}$ & $4.88 \pm 0.10^{*}$ \\
\hline $\begin{array}{l}\text { Peri.C } \\
(\mathrm{mm}) \\
\end{array}$ & $8.84 \pm 0.10$ & $8.67 \pm 0.11$ & $7.90 \pm 0.14^{\# *}$ & $8.11 \pm 0.08^{\# *}$ \\
\hline $\begin{array}{l}\text { Ct.Th } \\
(\mathrm{mm})\end{array}$ & $0.60 \pm 0.01$ & $0.61 \pm 0.01$ & $0.53 \pm 0.01^{\# *}$ & $0.52 \pm 0.01^{\# *}$ \\
\hline
\end{tabular}

\section{Trabecular compartment}

\begin{tabular}{|c|c|c|c|c|}
\hline $\begin{array}{l}\text { Tot.BMC } \\
(\mathrm{mg} / \mathrm{mm})\end{array}$ & $12.52 \pm 0.23$ & $11.66 \pm 0.27^{\#}$ & $12.03 \pm 0.31$ & $11.50 \pm 0.18^{\#}$ \\
\hline $\begin{array}{l}\text { Tot.vBMD } \\
\left(\mathrm{mg} / \mathrm{mm}^{3}\right)\end{array}$ & $886.17 \pm 22.24$ & $780.07 \pm 9.26^{\#}$ & $775.02 \pm 21.52^{\#}$ & $712.79 \pm 10.72^{\# * \neq}$ \\
\hline $\begin{array}{l}\text { Tot.Ar } \\
\left(\mathrm{mm}^{2}\right)\end{array}$ & $14.15 \pm 0.44$ & $14.93 \pm 0.31$ & $15.58 \pm 0.32^{\#}$ & $16.13 \pm 0.53^{\#}$ \\
\hline $\begin{array}{l}\text { Tb.BMC } \\
(\mathrm{mg} / \mathrm{mm})\end{array}$ & $3.80 \pm 0.16$ & $3.00 \pm 0.17^{\#}$ & $3.21 \pm 0.18^{\#}$ & $2.52 \pm 0.15^{m^{*} \neq}$ \\
\hline $\begin{array}{l}\text { Tb.vBMD } \\
\left(\mathrm{mg} / \mathrm{mm}^{3}\right)\end{array}$ & $583.23 \pm 17.03$ & $444.75 \pm 12.71^{\#}$ & $460.03 \pm 11.04^{\#}$ & $351.44 \pm 22.42^{\# * \neq}$ \\
\hline $\begin{array}{l}\text { Tb.Ar } \\
\left(\mathrm{mm}^{2}\right)\end{array}$ & $6.37 \pm 0.14$ & $6.72 \pm 0.14$ & $7.01 \pm 0.31^{\#}$ & $7.32 \pm 0.31^{\#^{*}}$ \\
\hline
\end{tabular}

Results are the means \pm S.E.M. $(n=8)$

\# vs. SHO-CON

vs. SHO-FAT

‡vs. OVX-CON where $\mathrm{P} \leq 0.05$ by ANOVA and post hoc Tukey test.

Abbreviations for cortical bone tissue: Tot.BMC - total slice bone mineral content; Tot.vBMD - total slice volumetric bone mineral density; $\mathrm{Tot}$.Ar - total slice bone area; $\mathrm{Ct}$.Ar - cortical bone area; Ct.BMC - cortical bone mineral content; Ct.vBMD - cortical volumetric bone mineral density; Ct.Th - cortical thickness; Peri.C - periosteal circumference; Endo.C - endocortical circumference. Abbreviations for trabecular bone tissue: Tot BMC - total slice bone mineral content; Tot $v B M D$

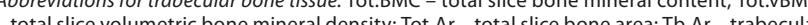
列 mineral density.

Peripheral quantitative computed tomography (pQCT). Dietary-induced obesity in SHO females significantly decreased the BMC and vBMD of the cortical compartment when measured in the femora $(\mathrm{P}<0.002)$ and tibiae mid shafts $(\mathrm{P}<0.02)$, compared to that of the SHO control rats (Tab, 2 and 3). A similarity was also observed in the degree of the resorption of the cortical compartment in both examined bones isolated from SHO females, compared with DIO and OVX rats fed the standard diet. Furthermore, the synergistic influence of ovariectomy and high-energy diet involved the most intensive resorption of femora and tibiae - with lowest values of BMC and vBMD of cortical compartment seen in $\mathrm{DIO}$ and OVX rats in relation to that of the control groups $(\mathrm{P}=0.0001)$. Experimental feeding and ovariectomy also affected the structural properties of the cortical bone tissue. The area of cortical compartment significantly decreased in the examined bones from both OVX groups $(\mathrm{P}<0.0002)$, while experimental feeding for inducing obesity (groups SHO-FAT and OVX-FAT) slightly tended towards higher values of Ct.Ar in relation to the $\mathrm{SHO}$ and OVX groups that had followed a standard diet. Similar relationships in Ct.Th were observed (Tab. 2 and 3).

A decrease was also noted in the bone mineral content ( $\mathrm{Tb}$. $\mathrm{BMC}$ ) and volumetric bone mineral density (Tb.vBMD) in the trabecular compartment of the femur $(\mathrm{P}<0.05)$ in relation to SHO-CON rats, with the lowest values seen in the OVX rat group following the high-energy diet. Experimental feeding with the high-energy diet increased the area of trabecular bone tissue of distal femur metaphysis in all experimental groups (SHO-FAT $-\mathrm{P}=0.0002$; OVX-CON $-\mathrm{P}=0.08$; OVX-FAT - P = 0.0002) (Tab. 2). Furthermore, tomographic analysis of tibiae documented a significant decrease of Tb.BMC in all experimental groups ( $v s$. SHO-CON group; with the lowest values in rats from the OVX-FAT group (P $<0.0001$ ) (Tab. 3). A similar relationship was observed in the Tb.vBMD of the proximal tibiae $(\mathrm{P}<0.0001)$. Moreover, ovariectomy (OVX-CON group) or the group following of a high-energy diet in the ovariectomized rats (OVX-FAT group), significantly increased the area of trabecular bone tissue, in comparison to the $\mathrm{SHO}-\mathrm{CON}$ group $(\mathrm{P}=0.05$ and $\mathrm{P}=0.003$, respectively) (Tab. 3 ).

Mechanical and structural properties of femur and tibiae. Analysis of femur and tibiae using the 3-point bending test showed that both the ovariectomy and high-energy diet decreased the Ultimate Strength $\left(\mathrm{F}_{\mathrm{max}}\right)$, Young Modulus $\left(\mathrm{E}_{\text {mod }}\right)$, as well as Work to the Limit of the Ultimate Strength $\left(\mathrm{W} / \mathrm{F}_{\max }\right)$ in adult female rats. Statistically significant ( $v s$. $\mathrm{SHO}-\mathrm{CON}$ ) lowest values were noted in the mechanical parameters of examined bones in females from the OVXFAT group (Fig. 1). Analysis of mechanical parameters based on the disintegration of the bone structure using the 3 -point bending test was confirmed by the measurement of SSI parameters (strain-strength index) estimated tomographically (pQCT) (Fig. 1).

Biochemical analysis. Total alkaline phosphatase (ALP) activity was significantly lower in all experimental groups in relation to that of SHO-CON $(\mathrm{P}<0.04)$ (Tab. 4). Osteocalcin concentration level was also lower in the experimental groups. A significant decrease of this biochemical marker of bone formation was particularly noticeable in OVXCON and OVX-FAT $(\mathrm{P}<0.05)$ rats. The high-energy diet, moreover, significantly increased the concentration of the CTX in the blood serum of females with respect to SHOCON group $(\mathrm{P}<0.0001)$. In addition, ovariectomy markedly elevated the level of CTX in the OVX-CON rats $(\mathrm{P}=0.03)$. The highest concentration of CTX was significantly evident in the blood serum of the ovariectomized rats following the high-energy diet (OVX-FAT) $(\mathrm{P}<0.0001)(\mathrm{Tab} .4)$. Moreover, while the DIO in SHO females (SHO-FAT) had no effect on the concentration of sclerostin in blood serum, ovariectomy increased the level of sclerostin, and the results noted in OVX-CON females group were the highest by $4.1 \%$, but were insignificant $(\mathrm{P}=0.081)$. Surprisingly, the concentration of sclerostin dramatically decreased (by $21.5 \%$ vs. SHO-CON) in females with DIO and established osteopenia (OVX-FAT), and was significantly the lowest in relation to all other groups in the study $(\mathrm{P}<0.0001)$ (Tab. 4). 


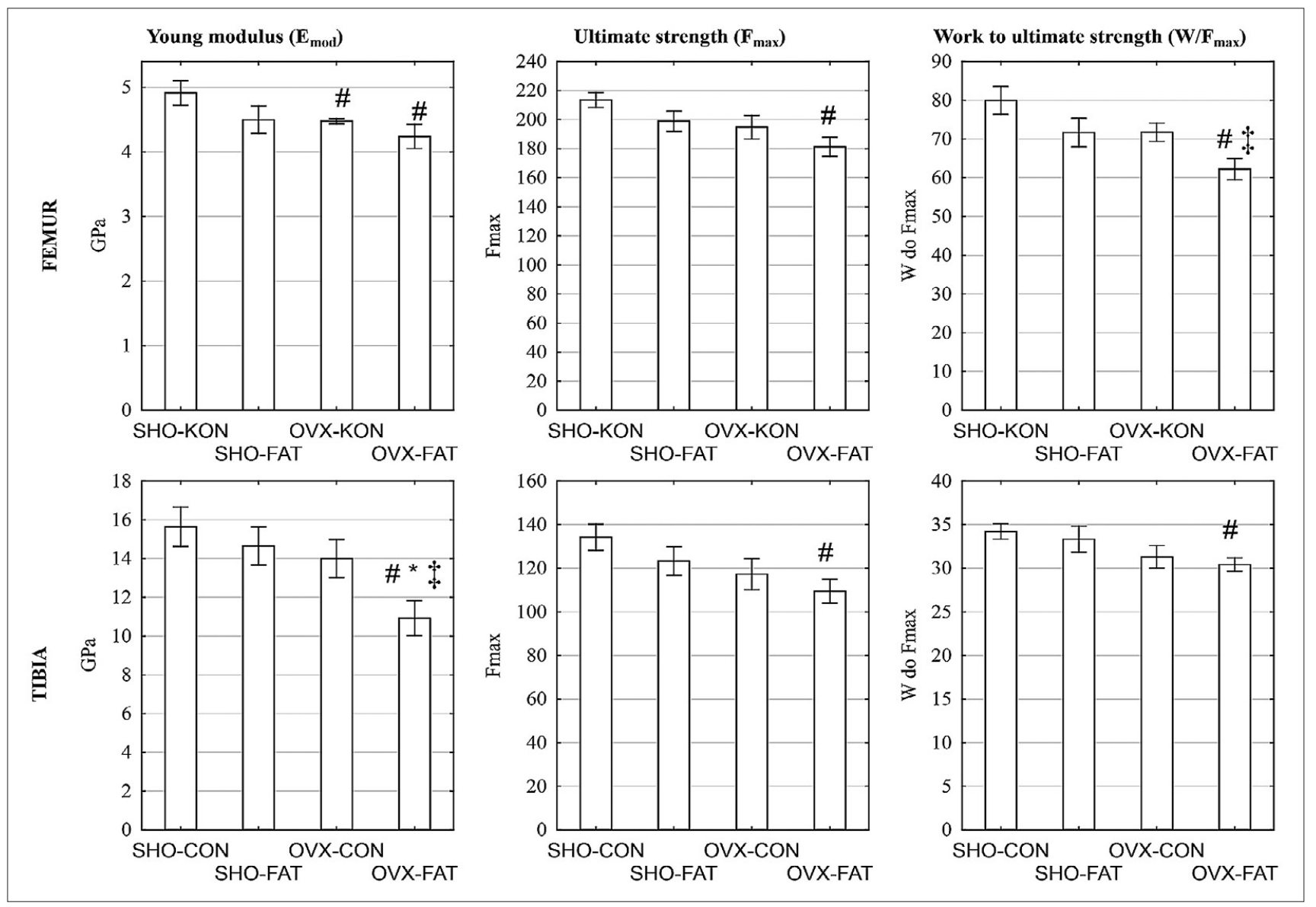

Figure 1. Mechanical parameters of isolated femur and tibiae established using three-point bending test. Results are the means \pm S.E.M. ( $n=8$ ). \# vs. SHO-CON; * vs. SHO-FAT; $\neq$ vs. OVX-CON where P $\leq 0.05$

The lowest total cholesterol (TC) concentration was noted in the blood serum of SHO-CON rats (Tab. 4), but the highenergy diet treatment increased the TC concentration in rats from the SHO-FAT group by $42.5 \%(\mathrm{P}=0.0009)$. An increased TC level (in relation to that of the $\mathrm{SHO}-\mathrm{CON}$ rats) was also noted in the OVX-CON females (4.9\%; $\mathrm{P}=$ 0.0012). Interestingly, the TC concentrations in SHO-FAT and OVX-CON females were at a similar level. The highest level of total cholesterol was significantly noticeable in the blood serum of OVX-FAT rats $(\mathrm{P}=0.00002 v s$. SHO-CON $)$. Furthermore, the concentration of TC in OVX-FAT rats was significantly higher than that in SHO-FAT $(\mathrm{P}=0.0024)$ and OVX-CON females $(\mathrm{P}=0.013)$ (Tab. 4). Similar relationships were observed in concentrations of LDL and triglycerides (TG); however, no statistically significant differences were observed between SHO-FAT and OVX-CON vs. OVX-FAT (Tab. 4).

\section{DISCUSSION}

The metabolism of bone tissue is dependent upon numerous factors. Here, the hormonal profile and nutritional status seem to play key roles. The importance of sex hormones for bone tissue homeostasis and the consequences of gonad malfunction in menopause or experimental ovariectomy are well described both in humans and animals [22-24]. Similar to other researchers, the authors of the current study also noted that ovariectomy influenced bone tissue, deceasing
Table 4. Biochemical markers of bone tissue metabolism and lipid profile measured in blood serum of sham-operated (SHO) and ovariectomized $(\mathrm{OVX})$ rats fed the standard (CON) or high-energy diet (FAT), respectively

\begin{tabular}{lcccc}
\hline & SHO-CON & SHO-FAT & OVX-CON & OVX-FAT \\
\hline $\begin{array}{l}\text { OC } \\
\text { (ng/ml) }\end{array}$ & $10.09 \pm 0.30$ & $9.94 \pm 0.30$ & $9.12 \pm 0.33^{*}$ & $9.18 \pm 0.37$ \\
\hline $\begin{array}{l}\text { CTX } \\
\text { (ng/ml) }\end{array}$ & $17.12 \pm 0.13$ & $19.99 \pm 0.47^{\#}$ & $18.29 \pm 0.05^{\#}$ & $21.45 \pm 0.21^{\# \neq}$ \\
\hline $\begin{array}{l}\text { ALP } \\
(\mathrm{U} / \mathrm{l})\end{array}$ & $163.28 \pm 3.65$ & $152.04 \pm 4.31^{\#}$ & $152.66 \pm 2.62^{\#}$ & $146.42 \pm 1.98^{\#}$ \\
\hline $\begin{array}{l}\text { Total } \\
\text { Cholesterol } \\
\text { (mg/dL) }\end{array}$ & $116.83 \pm 10.31$ & $166.83 \pm 2.82^{\#}$ & $175.00 \pm 5.83^{\#}$ & $199.14 \pm 3.94^{\# *}$ \\
\hline $\begin{array}{l}\text { Triglycerides } \\
\text { (mg/dL) }\end{array}$ & $435.83 \pm 21.79$ & $588.33 \pm 32.83^{\#}$ & $561.67 \pm 41.38^{\#}$ & $594.43 \pm 25.59^{\#}$ \\
\hline $\begin{array}{l}\text { LDL } \\
\text { (mg/dL) }\end{array}$ & $17.17 \pm 0.95$ & $24.00 \pm 0.97^{\#}$ & $25.17 \pm 0.60^{\#}$ & $26.57 \pm 0.69^{\#}$ \\
\hline $\begin{array}{l}\mathrm{HDL} \\
\text { (mg/dL) }\end{array}$ & $47.83 \pm 2.46$ & $34.68 \pm 1.82^{\#}$ & $35.12 \pm 3.05^{\#}$ & $24.77 \pm 1.97^{\# *}$ \\
\hline $\begin{array}{l}\text { Sclerostin } \\
\text { (mg/ml) }\end{array}$ & $13.28 \pm 0.13$ & $13.06 \pm 0.28$ & $13.82 \pm 0.07^{*}$ & $10.42 \pm 0.27^{\#^{* *}}$ \\
\hline
\end{tabular}

Results are the means \pm S.E.M. $(n=8)$

\# vs. SHO-CON

* vs. SHO-FAT

¥ vs. OVX-CON where $\mathrm{P} \leq 0.05$ by ANOVA and post hoc Tukey test.

OC - osteocalcin; CTX - C-terminal telopeptides of type I collagen; ALP - acaline phosphatase; LDL -low density lipoproteins; HDL - high density lipoproteins.

densitometric properties. However, the relationships between overweight or obesity and bone metabolism are 
still being debated. Some authors hold that fat tissue can exert osteoprotective influences [25-27]. In contrast, other researchers document that overweight or obesity impede bone growth and development $[28,29]$, or simply accelerate osteoresorption [30,31]. In the current study, it was observed that the dietary-induced obesity (DIO) in adult females (SHO-FAT group) lowered BMC and BMD in relation to SHO females treated with the control diet (SHO-CON). Similar results were noted by $\mathrm{Cao}$ et al. [32]. However, the current study is the first to document the similarity of intensity of bone loses involved by ovariectomy and DIO during the same period - 90 days.

The presented study performed a DXA examination of whole femora and tibiae isolated from ovariectomized rats (OVX-CON group) and SHO females with DIO (SHO-FAT group), and the results indicated that the values of f.BMD and f.BMC from SHO-FAT and OVX-CON females decreased to a similar degree, compared to control females. A more intensive loss of BMD and BMC was noted in animals simultaneously influenced by OVX and DIO.

Tomographic measurements of isolated femora and tibiae support earlier observations about differentiated sensitivity and intensity of metabolic changes in the cortical and trabecular compartments [33-35]. Cortical bone tissue is less sensitive then trabecula, and any changes of vBMD and BMC, as well as differences between particular groups, are less evident and less expressed [36, 37]. Despite this, it was noticed that both DIO or OVX markedly influenced $\mathrm{BMC}$ and vBMD measured by way of the mid-shaft of bone columns for total bone slice (Tot.BMC; Tot.vBMD), as well as separately for the cortical compartment (Ct.BMC; Ct.vBMD). What is more, the exclusive influence of high-energy diet or ovariectomy affected the cortical compartment to a similar degree, while the common influence of DIO and OVX involved the strongest effect, decreasing BMC and vBMD to the lowest values. Both OVX and DIO exerted influence upon the geometrical properties of the femoral and tibial mid-shaft of the column. In addition, ovariectomy induced resorption of bone tissue under the periosteum - significantly deceasing pericortical circumference (Peri.C) in relation to that of the SHO groups [38]. Of note, the high-energy diet had no significant influence on periosteal resorption and no differences were noted between the SHO groups or OVX groups of rats. In contrast to the periosteal surface effects, the DIO significantly elevated the volume of the medullar cavity in the femora and tibiae by way of increased endocortical resorption (increased Endo.C), compared to the groups receiving standard diet. In doing so, the metabolic changes under the periosteum and in the medullary cavity induce an enhanced thickness (Ct.Th) and area (Ct.Ar) of the cortical compartment. Furthermore, a significant decrease of these values was noted in the OVX groups, while the high-energy diet had no influence upon these parameters.

The pQCT analysis of the trabecular compartment revealed that the exclusive influence of OVX or DIO significantly decreased the Tb.vBMD and Tb.BMC, as established in the metaphysis of the examined bones. Bone-dependent differences were also observed between femora and tibiae. In the femora, osteopenic changes were more expressed and the extent of difference was statistically significant in the bones isolated from females with established osteopenia (OVXCON group), compared to other test groups. In addition, the Tb.vBMD and Tb.BMC values in the SHO-FAT and
OVX-CON group tibiae were similar. Moreover, it was seen that the inclusive influence of OVX and DIO (OVX-FAT group) exerted the strongest effect on the examined bones, dramatically decreasing their densitometric properties. Ovariectomy increased the total area of bone and area of trabecular compartment, compared to that of the SHO groups. Of note, the obtained results are in line with other studies performed with the use of mice [39] and rats [40] as animal models.

The mechanical properties of bone depend upon numerous factors. Among these are mineralization, structure, size and shape of deposited hydroxyapatite, as well as the spatial organization of collagen fibres [41-43]. This implies that bone tissue must be considered as a two-phase system of collagen fibres interlaced with hydroxyapatite crystals [44]. The data of the current study indicate that both highenergy diet and ovariectomy tended to lower the mechanical resistance of femora and tibiae. Indeed, significantly, the lowest mechanical properties were noted in the bones isolated from OVX females that received the high-energy diet.

Sclerostin has been regarded recently as an important inhibitor of bone tissue formation. As mentioned previously, the protein produced by the osteocytes inhibits the Wnt/ $\beta$ catenin pathway, and in this way limits the metabolic activity of osteoblasts [45]. What is more, numerous papers have dealt with pre-clinical [46] and clinical studies [47] on the use of sclerostin antibodies in treating experimental and postmenopausal osteoporosis. The results of the presented study partially support current opinion, and the increase of sclerostin concentration after the ovariectomy of females treated with the standard diet was noted. However, while the densitometric, structural or mechanic disturbances in femora and tibiae noted in OVX-CON were in general similar to that of SHO females with DIO, in the current study, no influence was observed of high-energy diet on the blood serum sclerostin concentration in SHO-FAT rats. What is more, a dramatic decrease was documented of the sclerostin level in the blood serum of females with established osteopenia and dietary-induced obesity (OVX-FAT). Additionally, analysis of the correlation between serum level of sclerostin and mechanical parameters was clearly positive $\left(\mathrm{E}_{\mathrm{mod}}-\mathrm{r}=0.42\right.$, $\left.\mathrm{P}>0.05 ; \mathrm{F}_{\max }-\mathrm{r}=0.43 ; \mathrm{P}<0.05, \mathrm{~W} / \mathrm{F}_{\max }-\mathrm{r}=0.53 ; \mathrm{P}<0.05\right)$, but the negative correlation between serum concentration of sclerostin and CTX - a marker of bone resorption $(r=-0.62$; $\mathrm{P}<0.05)$ was also quite evident.

\section{CONCLUSIONS}

Summarizing, increased fat tissue accumulation is a pivotal factor affecting the metabolism of bone tissue. The results obtained in the current study indicate that in adult female rats, obesity or/and ovariectomy increases the resorption of femora and tibiae, hence decreasing the densitometric and mechanical parameters. It must be noted that the degree of bone tissue degradation caused exclusively by ovariectomy was similar to that of obese sham-operated rats. Based on the serum level of sclerostin, bone losses induced by DIO seem to be independent from sclerostin-induced inhibition of the $\mathrm{Wnt} / \beta$-catenin pathway. This outcome may suggest that the usage of sclerostin anti-body in the treatment of osteoporosis can be ineffective. However, the presented observation should be confirmed by further studies and bio-molecular analysis 
of the sclerostin antibody effect on the Wnt/beta-catenin pathway of bone tissue metabolism.

\section{REFERENCES}

1. Rankinen T, Zuberi A, Chagnon YC, Weisnagel SJ, Argyropoulos G, Walts B, et al. The human obesity gene map: the 2005 update. Obesity (Silver Spring). 2006; 14(4): 529-644.

2. Haworth CM, Plomin R, Carnell S, Wardle J. Childhood obesity: genetic and environmental overlap with normal-range BMI. Obesity (Silver Spring). 2008; 16(7): 1585-90.

3. Ailhaud G. Adipose tissue as a secretory organ: from adipogenesis to the metabolic syndrome. C R Biol. 2006; 329(8): 570-655.

4. Bieńko M, Lis A, Wolski D, Radzki RP. Relationships between bone tissue and fat tissue. Med Wet. 2016; 72(4): 217-24.

5. Wolski D, Michalik J, Bieńko M, Radzki RP. Effects of obesity on health condition with an emphasis on bone tissues disorders. Eur J Clin Exp Med. 2018; 16(2): 117-22.

6. De Laet C, Kanis JA, Oden A, Johanson H, Johnell O, Delmas P, et al. Body mass index as a predictor of fracture risk: a meta-analysis. Osteoporos Int. 2005; 16(11): 1330-8.

7. Rezende Yanagihara G, Carminati Shimano R, Atsuko Tida J, Suzuki Yamanaka J, Yasuyo Fukada S, Mardegan Issa JP, et al. Influence of High-Fat Diet on Bone Tissue: An Experimental Study in Growing Rats. J Nutr Health Aging. 2017; 21(10): 1337-43.

8. Fantuzzi G. Adipose tissue, adipokines, and inflammation. J Allergy Clin Immunol. 2005; 115(5): 911-9.

9. Sharifi M, Ereifej L, Lewiecki EM. Sclerostin and skeletal health. Rev Endocrine Metab Dis. 2015; 16(2): 149-156.

10. Logan CY, Nusse R. The Wnt signaling pathway in development and disease. Annu Rev Cell Dev Biol. 2004; 20: 781-810.

11. Komiya Y, Habas R. Wnt signal transduction pathways. Organogenesis. 2008; 4(2): 68-75.

12. Kikuchi A, Yamamoto H, Sato A. Selective activation mechanisms of Wnt signaling pathways. Trends Cell Biol. 2009; 19(3): 119-29.

13. Rodda SJ, McMahon AP. Distinct roles for Hedgehog and canonical Wnt signaling in specification, differentiation and maintenance of osteoblast progenitors. Development. 2006; 133(16): 3231-44.

14. Gaudio A, Pennisi P, Bratengeier C, Torrisi V, Lindner B, Mangiafico $\mathrm{RA}$, et al. Increased sclerostin serum levels associated with bone formation and resorption markers in patients with immobilizationinduced bone loss. J Clin Endocrinol Metab. 2010; 95(5): 2248-53.

15. Choi HY, Dieckmann M, Herz J, Niemeier A. Lrp4, a novel receptor for Dickkopf 1 and sclerostin, is expressed by osteoblasts and regulates bone growth and turnover in vivo. PLoS One. 2009; 4(11): e7930.

16. Tatsumi S, Nagamoto K, Ogata M, Miyamoto K. [Bone and Nutrition. Sclerostin and bone metabolism]. Clinical calcium. 2015; 25(7): 1043-7.

17. Register TC, Hruska KA, Divers J, Bowden DW, Palmer ND, Carr JJ, et al. Sclerostin is positively associated with bone mineral density in men and women and negatively associated with carotid calcified atherosclerotic plaque in men from the African American-Diabetes Heart Study. J Clin Endocrinol Metab. 2014; 99(1): 315-21.

18. Polyzos SA, Anastasilakis AD, Bratengeier C, Woloszczuk W, Papatheodorou A, Terpos E. Serum sclerostin levels positively correlate with lumbar spinal bone mineral density in postmenopausal womenthe six-month effect of risedronate and teriparatide. Osteoporosis international: a journal established as result of cooperation between the European Foundation for Osteoporosis and the National Osteoporosis Foundation of the USA. 2012; 23(3): 1171-6.

19. Armamento-Villareal R, Sadler C, Napoli N, Shah K, Chode S, Sinacore $\mathrm{DR}$, et al. Weight loss in obese older adults increases serum sclerostin and impairs hip geometry but both are prevented by exercise training. J Bone Mineral Res. 2012; 27(5): 1215-21.

20. Tubic B, Zeijlon R, Wennergren G, Obermayer-Pietsch B, Marild S, Dahlgren J, et al. Randomised study of children with obesity showed that whole body vibration reduced sclerostin. Acta Paediatrica. 2019; 108(3): 502-513.

21. National Research Council (US) Subcommittee on Laboratory Animal Nutrition. Nutrient Requirements of Laboratory Animals. Edition FR, editor. Washington (DC): National Academies Press (US); 1995.
22. Radzki RP, Bieńko M, Puzio I, Studziński T. Effect of oestradiol and tamoxifen on the mechanical parameters of the femora and humera in broiler chickens. Med Wet. 2003; 59(12): 1090-1094.

23. Narla RR, Ott SM. Bones and the sex hormones. Kidney Internat. 2018; 94(2): 239-42.

24. Zha XY, Hu Y, Pang XN, Zhu JH, Chang GL, Li L. The association between sex hormone-binding globulin gene polymorphism with bone mineral density. Steroids. 2016; 106: 9-18.

25. Cherif R, Mahjoub F, Sahli H, Cheour E, Vico L, Sakly M, et al. Positive Association of Obesity and Insulin Resistance With Bone Mineral Density in Tunisian Postmenopausal Women. J Clin Densitometry. 2018; 21(2): 163-71.

26. Savvidis C, Tournis S, Dede AD. Obesity and bone metabolism. HormInt J Endocrino. 2018; 17(2): 205-17.

27. Farr JN, Dimitri P. The Impact of Fat and Obesity on Bone Microarchitecture and Strength in Children. Calcified Tissue International. 2017; 100(5): 500-13.

28. Gao F, Lv TR, Zhou JC, Qin XD. Effects of obesity on the healing of bone fracture in mice. J Orthopaedic Surg Res. 2018; 13(1): 145.

29. Chen ZB, Liu H, Li W, Jia SN, Zhang Y, Li BB. Correlation between obesity and bone health in Chinese children and adolescents. Inter J Clin Exp Med. 2017; 10(3): 5270-7.

30. Leslie WD, Morin SN, Majumdar SR, Lix LM. Effects of obesity and diabetes on rate of bone density loss. Osteoporosis Int. 2018; 29(1): 61-7.

31. Li W, Xu P, Wang CZ, Ha XD, Gu YJ, Wang Y, et al. The effects of fat-induced obesity on bone metabolism in rats. Obes Res Clin Pract. 2017; 11(4): 454-63.

32. Cao JJ, Gregoire BR, Gao H. Obesity Induced by High Dietary Fat Leads to Increased Bone Resorption Marker, TRAP, and Decreased Bone Mass in Mice. J Bone Min Res. 2008; 23: S432-S.

33. Radzki RP, Bieńko M, Filip RS. Influence of strontium ranelate on mineral and mechanical properties of the femur in orchidectomized rats. Med Wet. 2007; 63(12): 1630-1634.

34. Urasopon N, Hamada Y, Cherdshewasart W, Malaivijitnond S. Preventive effects of Pueraria mirifica on bone loss in ovariectomized rats. Maturitas. 2008; 59(2)

35. Ferretti M, Cavani F, Roli L, Checchi M, Magaro MS, Bertacchini J, et al. Interaction among Calcium Diet Content, PTH (1-34) Treatment and Balance of Bone Homeostasis in Rat Model: The Trabecular Bone as Keystone. Int J Mol Sci. 2019; 20(3).

36. Radzki RP, Bieńko M, Pierzynowski SG. Anti-osteopenic effect of alpha-ketoglutarate sodium salt in ovariectomized rats. J Bone Miner Metab. 2012; 30(6): 651-659.

37. Dobrowolski P, Tomaszewska E, Radzki RP, Bieńko M, Wydrych J, Zdybel A, et al. Can 2-oxoglutarate prevent changes in bone evoked by omeprazole? Nutrition. 2013; 29(3): 556-61

38. Saxon LK, Turner CH. Estrogen receptor beta: the antimechanostat? Bone. 2005; 36(2): 185-192.

39. Seidlova-Wuttke D, Nguyen BT, Wuttke W. Long-term effects of ovariectomy on osteoporosis and obesity in estrogen-receptor-betadeleted mice. Comp Med. 2012; 62(1): 8-13.

40. Seidlova-Wuttke D, Hesse O, Jarry H, Christoffel V, Spengler B, Becker $\mathrm{T}$, et al. Evidence for selective estrogen receptor modulator activity in a black cohosh (Cimicifuga racemosa) extract: comparison with estradiol-17beta. Eur J Endocrinol. 2003; 149(4): 351-62.

41. Mosekilde L, Mosekilde L, Danielsen CC. Biomechanical competence of vertebral trabecular bone in relation to ash density and age in normal individuals. Bone. 1987; 8(2): 79-85.

42. Ciarelli TE, Fyhrie DP, Schaffler MB, Goldstein SA. Variations in three-dimensional cancellous bone architecture of the proximal femur in female hip fractures and in controls. J Bone Miner Res. 2000; 15(1): $32-40$.

43. Dempster DW. The contribution of trabecular architecture to cancellous bone quality. J Bone Miner Res. 2000; 15(1): 20-3.

44. Knott L, Bailey AJ. Collagen cross-links in mineralizing tissues: A review of their chemistry, function, and clinical relevance. Bone. 1998; 22(3): 181-7.

45. Lewiecki EM. Role of sclerostin in bone and cartilage and its potential as a therapeutic target in bone diseases. Ther Adv Musculoskelet Dis. 2014; 6(2): 48-57.

46. Ominsky MS, Boyce RW, Li X, Ke HZ. Effects of sclerostin antibodies in animal models of osteoporosis. Bone. 2017; 96: 63-75.

47. Rachner TD, Hofbauer L, Gobel A, Tsourdi E. Novel therapies in osteoporosis: PTH-related peptide analogues and inhibitors of sclerostin. J Mol Endocrinol. 2019; 62(2): R145-R154. 